\title{
СИНТЕЗ АЛКИЛАМИНОЭТИЛСУЛЬФАТОВ
}

В последние годы большое значение приобретает разработка новых поверхностно-активных веществ (ПАВ), обладающих повышенной моющей способностью без добавления к ним триполифосфата натрия, который вызывает обильный рост вредных сине-зеленых водорослей. В связи с этим представляет интерес изучение ПАВ, имеющих аминогруппу.

В некоторых работах имеются сведения о том, что алкиламиноэтилсульфонаты (R $\left.\mathrm{NHCH}_{2} \mathrm{CH}_{2} \mathrm{SO}_{3} \mathrm{Na}\right)$ обладают удовлетворительными поверхностно-активными свойствами и моющей способностью [1]. Отсутствуют данные о растворимости и моющей способности индивидуальных соединений этого типа, и не выявлена зависимость поверхностно-активных свойств растворов от структуры алкиламиноэтилсульфонатов. Данные о синтезе и свойствах алкиламиноэтилсульфатов и их натриевых солей отсутствуют вообще.

Целью настоящей работы являлось обсуждение экспериментальных данных, полученных по синтезу алкиламиносульфатов, и изучение свойств индивидуальных препаратов.

Алкиламиносульфаты можно получить сульфаталкилированием:

$$
\begin{aligned}
& \mathrm{RBr}+\mathrm{H}_{2} \mathrm{NCH}_{2} \mathrm{CH}_{2} \mathrm{OSO}_{3} \mathrm{Na} \longrightarrow \underset{\text { (или } \mathrm{ROH} \text { ) }}{\mathrm{RNHCH}_{2} \mathrm{CH}_{2} \mathrm{OSO}_{3} \mathrm{Na}+\mathrm{HBr} \text {. }} \text { (или } \mathrm{H}_{2} \mathrm{O} \text { ) }
\end{aligned}
$$

На практике эта реакция используется сравнительно редко [2]. В препаративных условиях более удобно получать алкиламиносульфаты путем сульфатирования соответствующих аминоспиртов:

$$
\mathrm{RNHCH}_{2} \mathrm{CH}_{2} \mathrm{OH} \stackrel{\mathrm{SO}_{3}}{\longrightarrow} \mathrm{RNHCH}_{2} \mathrm{CH}_{2} \mathrm{OSO}_{3} \mathrm{H} \stackrel{\mathrm{NaOH}}{\longrightarrow} \mathrm{RNHCH}_{2} \mathrm{CH}_{2} \mathrm{OSO}_{3} \mathrm{Na} \text {. }
$$

В литературе описаны некоторые способы синтеза нормальных алкиламиноспиртов. Наиболее важными из них являются:

a)

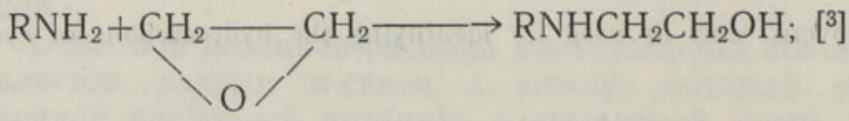

б) $\mathrm{RNH}_{2}+\mathrm{ClCH}_{2} \mathrm{CH}_{2} \mathrm{OH} \longrightarrow \mathrm{RNHCH}_{2} \mathrm{CH}_{2} \mathrm{OH}+\mathrm{HCl}$; [ [ ]

B) $\mathrm{RBr}+\mathrm{NH}_{2} \mathrm{CH}_{2} \mathrm{CH}_{2} \mathrm{OH} \longrightarrow \mathrm{RNHCH}_{2} \mathrm{CH}_{2} \mathrm{OH}+\mathrm{HBr}$; [4, 5] 
r) $\mathrm{RC}_{\mathrm{H}}^{\mathrm{O}}+\mathrm{NH}_{2} \mathrm{CH}_{2} \mathrm{CH}_{2} \mathrm{OH} \underset{\mathrm{H}_{2}}{\rightarrow} \rightarrow \mathrm{RCH}_{2} \mathrm{NHCH}_{2} \mathrm{CH}_{2} \mathrm{OH}$; [6]

д) $\mathrm{RNH}_{2}+\mathrm{ClCOOCH}_{2} \mathrm{CH}_{2} \mathrm{Cl} \longrightarrow \mathrm{RNHCOOCH} \mathrm{CH}_{2} \mathrm{Cl}+\mathrm{HCl}$<smiles>CC1CN(C(=O)OCC(=O)O)C(=O)O1</smiles>

$\mathrm{RNHCH}_{2} \mathrm{CH}_{2} \mathrm{OH}+\mathrm{CO}_{2}$. [7]

Сравнительно простым способом, обеспечивающим достаточную чистоту получаемых продуктов, является синтез нормальных алкиламиноспиртов на основе галоидалканов и моноэтаноламина. Параллельно с алкиламиноэтилсульфатами были синтезированы алкилметиламиноэтилсульфаты ( $\left.\mathrm{R}-\mathrm{N}-\mathrm{CH}_{2} \mathrm{CH}_{2} \mathrm{OSO}_{3} \mathrm{Na}\right)$ для определения влияния активного<smiles>C[In]</smiles>

водорода в молекуле поверхностно-активных веществ, содержащих аминогруппу. Этот синтез проводился по схеме:

$$
\mathrm{RNHCH}_{2} \mathrm{CH}_{2} \mathrm{OH}+\mathrm{CH}_{3} \mathrm{I} \longrightarrow \underset{\mathrm{CH}_{3}}{\mathrm{R}}-\underset{\mathrm{CH}_{2}}{\mathrm{~N}}-\mathrm{CH}_{2} \mathrm{CH}_{2} \mathrm{OH} .\left[^{8}\right]
$$

Аминоспирты сульфатировались комплексом сульфотриоксида и диоксана [9], что обеспечивало селективность этой реакции по гидроксильной группе без сульфоаминирования.

Для характеристики синтезированных соединений использовались методы спектрального анализа и газожидкостной хроматографии. Определялись элементарный состав и содержание аминных и гидроксильных групп $\left[{ }^{10}\right]$.

\section{Экспериментальная часть}

Синтез алкиламиноэтанолов (в качестве примера приводится методика синтеза н-дециламиноэтанола). В круглодонную колбу, снабженную обратным холодильником, помещали 165 г (2,7 моля) свежедистиллированного моноэтаноламина и 133 г (0,6 моля) бромистого децила. Растворителем использовали этанол (450 мл). Продолжительность реакции 20 , температура $80^{\circ} \mathrm{C}$. После окончания реакции спирт отгоняли и остаток выливали в посуду, где находился раствор едкого натра $(0,6$ моля $\mathrm{NaOH}$, растворенного в 620 мл воды). Смесь помещали в делительную воронку и отделяли масляный слой. Водяной слой дважды экстрагировали эфиром. Эфирные экстракты и масляный слой объединяли и пять раз промывали водой (каждый раз по 75 мл воды). Экстракты высушивали над твердой щелочью. После отгонки эфира продукт подвергали вакуумной дистилляции. При синтезе аминоспиртов с более короткой алкильной цепью продолжительность реакции уменьшалась, так при синтезе гексиламиноэтанола реакция продолжалась 8 .

Чистоту полученных алкиламиноэтанолов проверяли на хроматографе УХ-2. Твердым носителем служил хромосорб W (размер зерен 0,160,18 мм), неподвижной фазой - полиэтиленгликоль (молекулярный вес $15000) 15 \%$ на твердый носитель. Использовалась медная колонка длиной 3 и и диаметром 6 мм. Температура колонки $182^{\circ}$, чувствительность 5. 
Рис. 1. Хроматограмма алкиламиноэтанолов, I - гексиламиноэтанол, II - октиламиноэтанол, III - дециламиноэтанол.

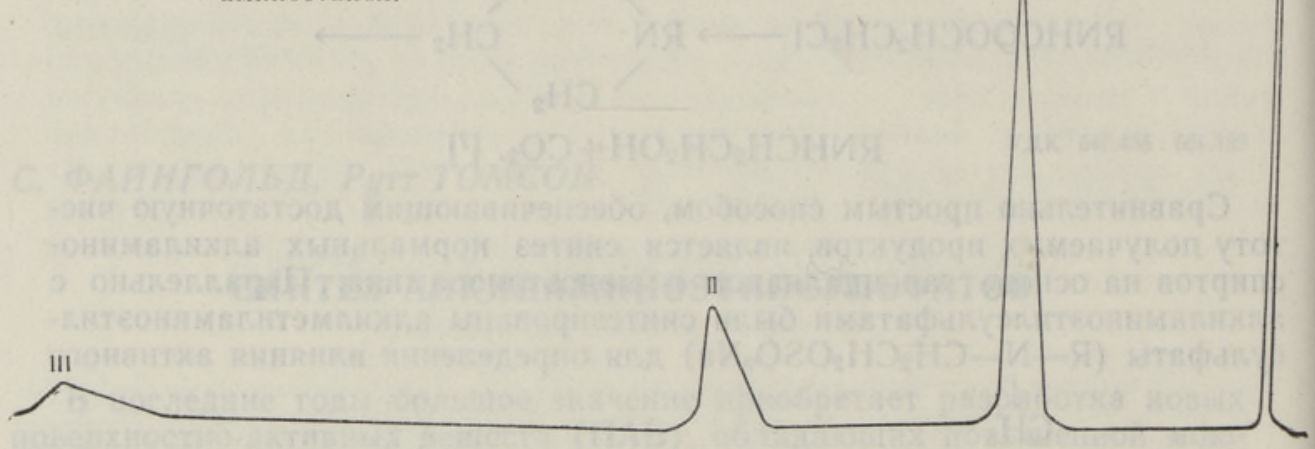

Хроматограмма спиртов приведена на рис. 1. Относительные времена удерживания:

$\begin{array}{ll}\text { гексиламиноэтанол } & 1 \\ \text { октиламиноэтанол } & 2,19 \\ \text { дециламиноэтанол } & 4,69\end{array}$

Полученные соединения охарактеризованы ИК-спектрами, снятыми на UR-10 (см. рис. 2). Они содержат набор интенсивных полос поглощения в области $1000-1220,1380-1500$ и $2800-3000 \mathrm{~cm}^{-1}$, т. е. характеризуют первичные алкиламиноспирты. В области $2790 \mathrm{~cm}^{-1}$ полоса поглощения появляется в соединениях, содержащих $\mathrm{N}-\mathrm{CH}_{3}$-группу. По этому признаку можно определить отсутствие активного водорода при азоте.

Физико-химические свойства синтезированных алкиламиноэтанолов приведены в табл. 1.

Синтез алкилметиламиноэтанолов (на примере синтеза децилметиламиноэтанола). В круглодонную колбу, снабженную обратным холодильником и термометром, помещали 146,3 г (0,73 моля) дециламиноэтанола и добавляли 157 г $(1,1$ моля) охлажденного иодистого метила. Реакция велась в течение 18 ч при температуре $50-60^{\circ}$ (при синтезе додецилметиламиноэтанола температура была $70-80^{\circ}$ ). Затем к реакционной смеси прибавляли 29,2 г (0,73 моля) едкого натра, растворенного в 70 мл воды. Спирты экстрагировали эфиром и вытяжку высушивали над твердым едким натром. После отгонки эфира аминоспирты выделяли вакуумной дистилляцией. Физико-химические свойства продуктов приведены в табл. 2.

Сульфатирование аминоспиртов. Во избежание сульфирования по водороду аминной группы сульфатирование проводилось комплексом диоксана с сульфотриоксидом при $25^{\circ}$. После перемешивания в течение двух часов полученный продукт обрабатывали водой. Сульфоэфир нейтрализовали $15 \%$-ной щелочью до $\mathrm{pH} 7$ и активное вещество выделяли обычным способом, однако для получения более чистого продукта необходима была дополнительная обработка абсолютным ацетоном. При нейтрализации до рН 7 получаются внутренние соли, которые при избытке 


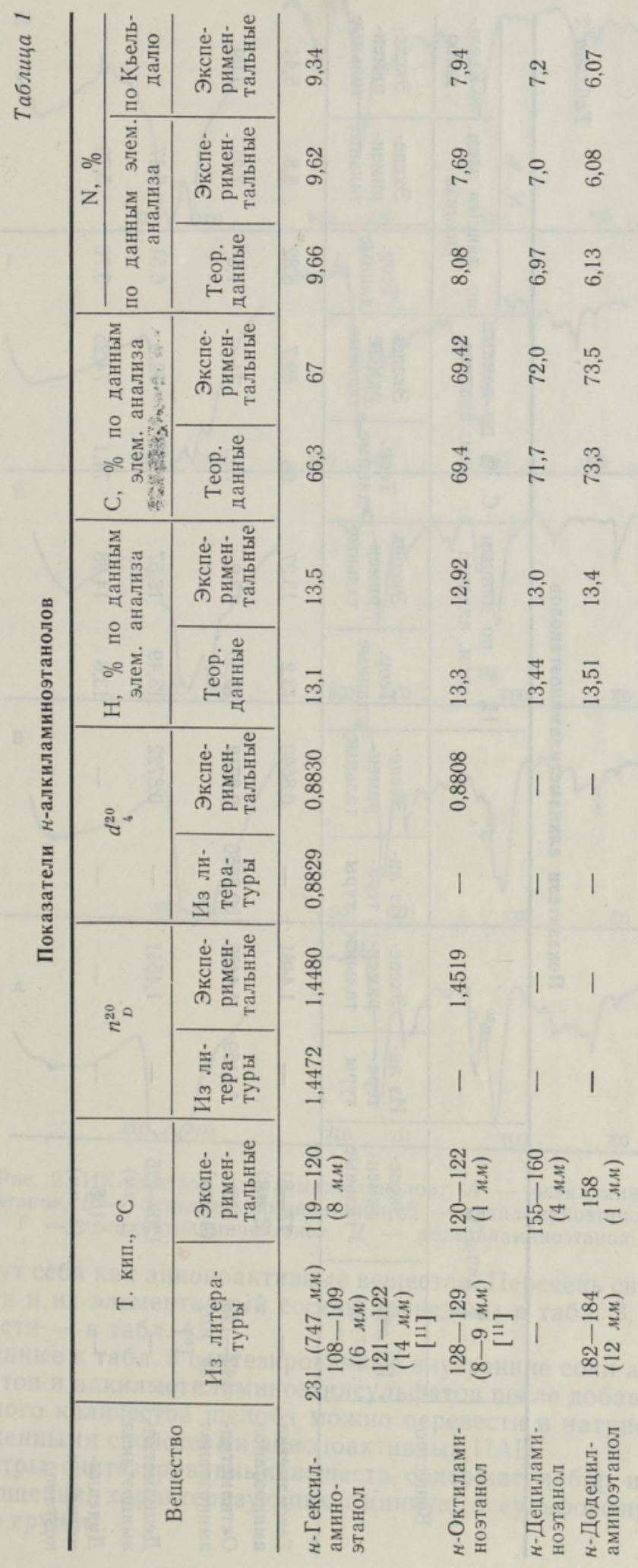




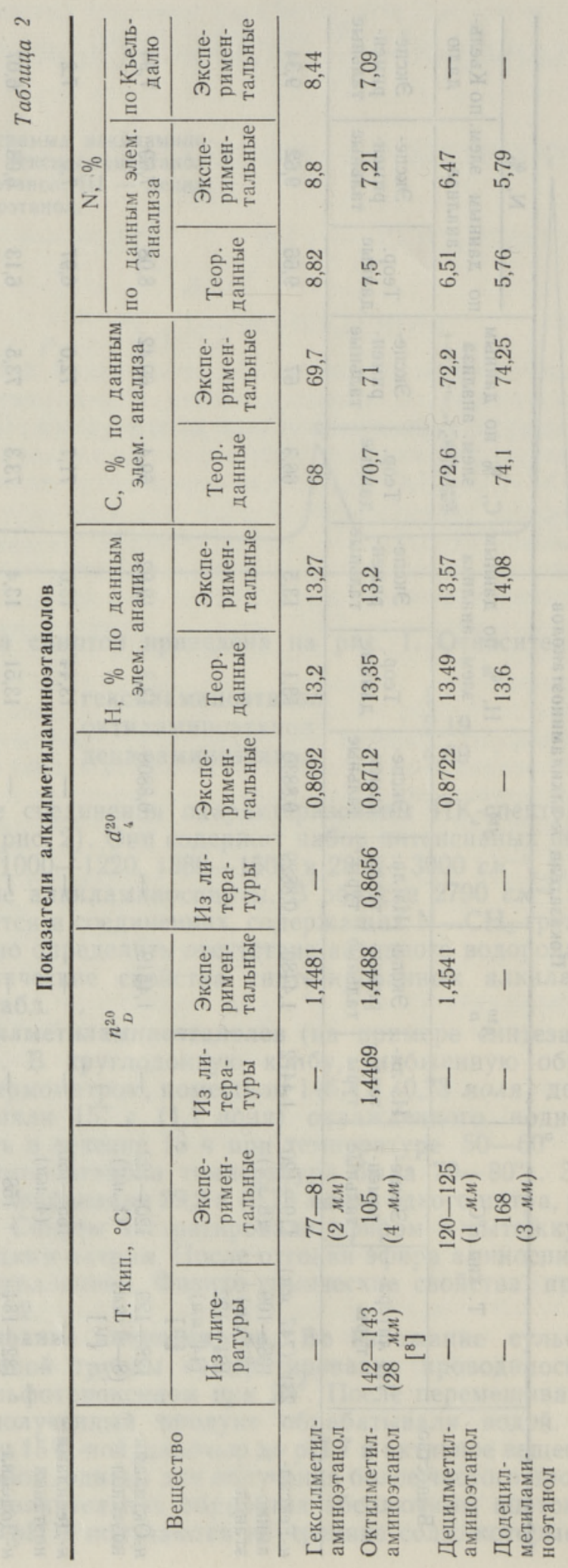



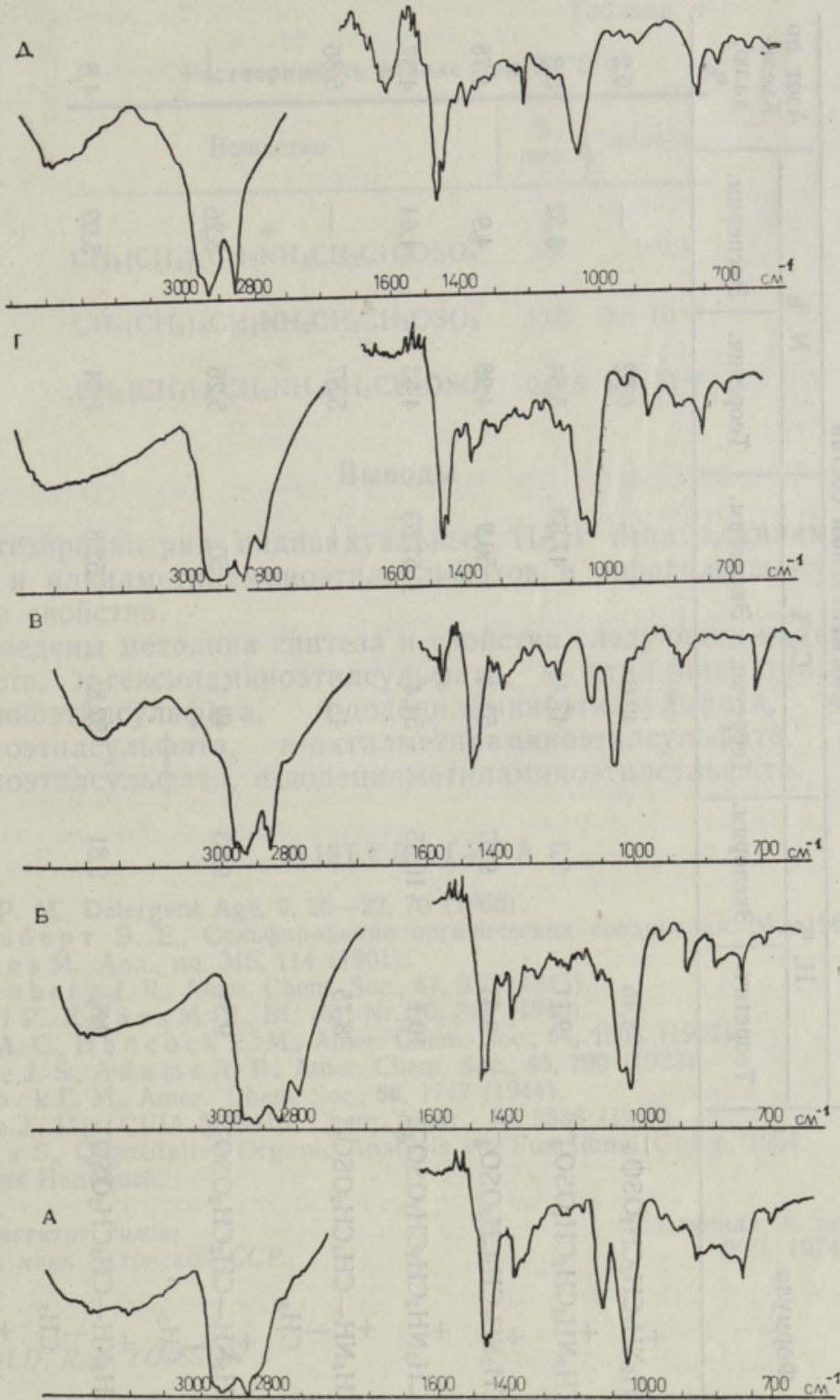

Рис. 2. ИК-спектры алкиламиноэтанолов: $A$ - октиламиноэтанол, $E$ - октилметиламиноэтанол, $B$ - дециламиноэтанол, $\Gamma$ - децилметиламиноэтанол, Д - додециламиноэтанол.

щелочи ведут себя как анионоактивные вещества. Перечень синтезированных веществ и их элементарный состав приведены в табл. 3, результаты растворимости - в табл. 4 .

Приведенные в табл. 3 синтезированные внутренние соли алкиламиноэтилсульфатов и алкилметиламиноэтилсульфатов после добавления эквимолекулярного количества щелочи можно перевести в натриевые соли с явно выраженными свойствами анионоактивных ПАВ.

ИК-спектры синтезированных веществ содержат набор интенсивных полос поглощения, характеризующих аминную и сульфоэфирную функциональные группы. 


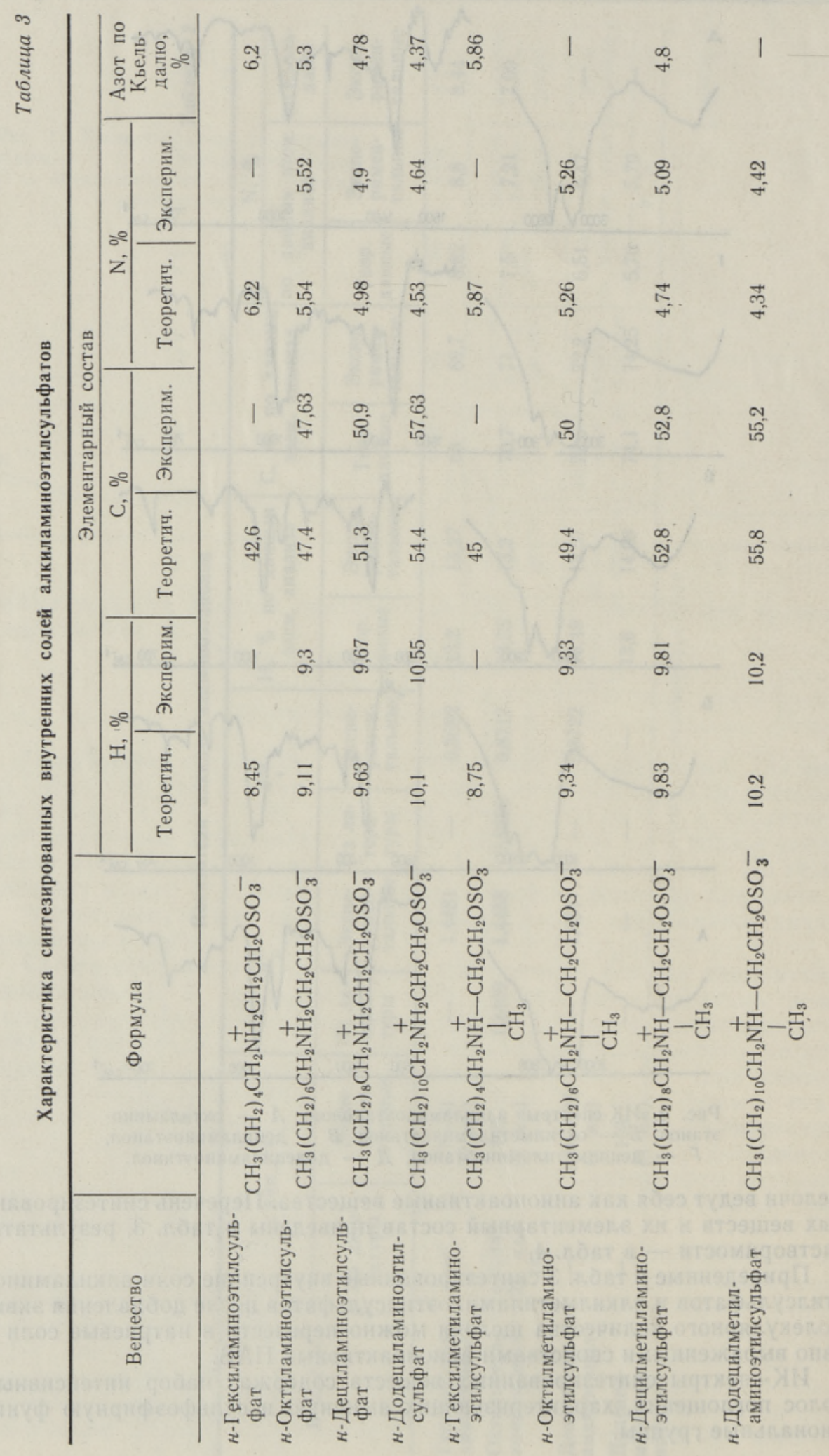


